\title{
Numerical Study of Simultaneous Multiple Fracture Propagation in Changning Shale Gas Field
}

\author{
Jun Xie ${ }^{1}$, Haoyong Huang ${ }^{1,2, *}$, Yu Sang ${ }^{1}$, Yu Fan ${ }^{1}$, Juan Chen ${ }^{1}$, Kan Wu ${ }^{3, *}$ and Wei $\mathrm{Yu}^{3,4}$ \\ 1 Petrochina Southwest Oil\&Gasfield Company, Chengdu 610017, China; xiejun01@petrochina.com.cn (J.X.); \\ sangy@petrochina.com.cn (Y.S.); fanyu@petrochina.com.cn (Y.F.); c_juan@petrochina.com.cn (J.C.) \\ 2 School of Petroleum Engineering, China University of Petroleum, Qingdao 266555, China \\ 3 Harold Vance Department of Petroleum Engineering, Texas A\&M University, College Station, TX 75254, \\ USA; yuwei127@gmail.com \\ 4 Hildebrand Department of Petroleum and Geosystems Engineering, The University of Texas at Austin, \\ Austin, TX 78712, USA \\ * Correspondence: huang_hy@petrochina.com.cn (H.H.); kan.wu@pe.tamu.edu (K.W.); \\ Tel.: +86-028-86018593 (H.H.); +86-010-5125652857 (K.W.)
}

Received: 28 February 2019; Accepted: 4 April 2019; Published: 8 April 2019

check for updates

\begin{abstract}
Recently, the Changning shale gas field has been one of the most outstanding shale plays in China for unconventional gas exploitation. Based on the more practical experience of hydraulic fracturing, the economic gas production from this field can be optimized and gradually improved. However, further optimization of the fracture design requires a deeper understanding of the effects of engineering parameters on simultaneous multiple fracture propagation. It can increase the effective fracture number and the well performance. In this paper, based on the Changning field data, a complex fracture propagation model was established. A series of case studies were investigated to analyze the effects of engineering parameters on simultaneous multiple fracture propagation. The fracture spacing, perforating number, injection rate, fluid viscosity and number of fractures within one stage were considered. The simulation results show that smaller fracture spacing implies stronger stress shadow effects, which significantly reduces the perforating efficiency. The perforating number is a critical parameter that has a big impact on the cluster efficiency. In addition, one cluster with a smaller perforating number can more easily generate a uniform fracture geometry. A higher injection rate is better for promoting uniform fluid volume distribution, with each cluster growing more evenly. An increasing fluid viscosity increases the variation of fluid distribution between perforation clusters, resulting in the increasing gap between the interior fracture and outer fractures. An increasing number of fractures within the stage increases the stress shadow among fractures, resulting in a larger total fracture length and a smaller average fracture width. This work provides key guidelines for improving the effectiveness of hydraulic fracture treatments.
\end{abstract}

Keywords: cluster efficiency; perforating number; Changning shale gas; multiple fracture propagation

\section{Introduction}

The Changning shale gas field in Sichuan Basin is well known as the main shale gas production area in China, and has begun commercial production since 2012. With less than a decade of production, there is still much to learn about the most efficient way to produce shale gas. With the increasing practical experience of hydraulic fracturing, the economic shale gas production from this field is able to be optimized and gradually improved [1]. The production of single shale-gas wells has been continuously improved and the average daily production has increased from $11.1 \times 10^{4} \mathrm{~m}^{3}$ to $28 \times 10^{4} \mathrm{~m}^{3}$. However, the average well production rate and estimated ultimate recovery (EUR) are significantly lower than shale gas production in North America [2-4]. 
The technique of multi-stage hydraulic fracturing is the key to develop unconventional gas reservoirs [5-8]. The production in the Haynesville shale demonstrates that one of the most effective ways to increase production is to maximize the number of fracture initiation points along the lateral. Because of the limited drainage radius of the created fractures, the well production increases while the spacing between each perforated cluster interval decreases. The recent completions in the Haynesville shale show that many operators are completing wells with tighter cluster spacing than previously attempted, and this trend has continued [9]. However, when the completions for increasing the number of clusters in one stage are used in the Changning field, the well production is not significantly increased.

The complex fracture geometry is often generated and predicted in shale gas reservoirs rather than simple planar fractures through advanced fracture diagnostic and microseismic monitoring results [10]. One usually considers that increasing the perforation clusters in one stage can generate a similar number of fractures after hydraulic fracturing. However, production logging and tracer detection demonstrated that not all fractures along the horizontal wellbore can effectively propagate [11-15]. Fracturing fluids and proppants do not enter into each cluster evenly. Some clusters have a large proportion of the intended liquid and proppant and generate "super" fractures, resulting in other clusters accepting very little fluid to grow. As a result, the difference of shale gas production between different clusters along the lateral is very big. The data of the production logs from the wells of the Sichuan Basin with 4-5 perforation clusters in one stage indicated that some clusters may be ineffective and do not contribute to production. However, the further optimization of the fracture design requires a better understanding of the effects of engineering parameters on simultaneous multiple fracture propagation. The fracture propagation model has been widely used in unconventional reservoirs for the completion design, such as the Permian Basin and Eagle Ford Shale [16-18]. Through the modeling research, optimization strategies have been achieved, which support the improvement of single well production. The optimal fracture design can materially increase the effective fracture number and enhance the well productivity. However, the rock mechanics parameters used in the simulation are the actual data of Changning, which are significantly different from US fields. The minimum horizontal stress and the Young's modulus are the different parameters used for this specific field. The minimum horizontal stress gradient of Changning is $0.0249 \mathrm{MPa} / \mathrm{m}$, while the minimum horizontal stress gradient of US fields is $0.0199 \mathrm{MPa} / \mathrm{m}$. The Young's modulus is about twice as much as that in US fields. Consequently, the multistage fracturing completion of the Changing field should be optimized to achieve a high cluster efficiency and increase the opportunities to distribute fluid and proppant evenly across all targeted clusters. In this paper, based on the complex fracture propagation model (XFRAC) and the Changning field data, a series of case studies were performed to investigate the effects of multiple engineering parameters on multiple fracture propagation. The fracture spacing, perforating number, injection rate, fluid viscosity and number of fractures within one stage were studied. For a deeper understanding of the complex physics related to simultaneous multiple fracture propagation and evaluating the uniformity of the fracture length, three perforation clusters in a stage were simulated, and the deviation of the normalized fracture length was calculated. The description of the model is presented in the following section.

\section{Methodology}

A complex fracture propagation model, developed by $\mathrm{Wu}$ [19], was used to simulate simultaneous multiple fracture propagation in shale gas formation. The rock deformation and fluid flow were iteratively coupled in the model. The rock deformation was modeled by a simplified 3D displacement discontinuity method [20]. The shear and normal displacement discontinuities were calculated for each fracture element. The normal displacement discontinuity is the opening of fractures, and the shear displacement discontinuity is used to predict the fracture propagation path at each time step. A non-planar fracture geometry will be induced if the shear displacement discontinuity is nonzero. To improve the computation efficiency, the simplified displacement discontinuity method eliminated 
the discretization in the vertical (fracture height) direction. The solution of the method can be made explicit as follows:

$$
\begin{aligned}
\sigma_{s L}^{i} & =\sum_{j=1}^{N} A_{s L, s L}^{i j} D_{s L}^{j}+\sum_{j=1}^{N} A_{s L, n n}^{i j} D_{n}^{j} \\
\sigma_{n n}^{i} & =\sum_{j=1}^{N} A_{n n, s L}^{i j} D_{s L}^{j}+\sum_{j=1}^{N} A_{n n, n n}^{i j} D_{n}^{j}
\end{aligned}
$$

where $i$ and $j$ represents elements $i$ and $j, N$ is the total element number, $D_{n}^{j}$ is a normal displacement discontinuity on element $j$, and $D_{s L}^{j}$ is a shear displacement discontinuity on element $j . \sigma_{s L}^{i}$ and $\sigma_{n n}^{i}$ are given traction boundary conditions. The distribution of pressure along the fracture path can be computed by the fluid flow model, which can provide these tractions. The constitutive model is based on the assumption of the plane-strain and elastic deformation. $A_{n n, s L}^{i j}$ is the coefficient matrix that can give the normal stress at element $i$ because of a shear displacement discontinuity at element $j . A_{n n, n n}^{i j}$ represents the normal stress at element $i$ induced by an opening displacement discontinuity at element $j$. Analogous meanings can be attributed to $A_{s L, s L}^{i j}$ and $A_{s L, n n}^{i j}$. The detailed derivation of the model can be found from the work by $\mathrm{Wu}[19]$.

The fluid flow in the shale gas wellbore and each fracture are fully coupled, similar to the electric circuit network. The flow rate of every fracture is similar to the current, and the pressure is analogous to the electric potential. We applied Kirchoff's first and second laws to compute the flow rate distribution among every fracture within a stage. The total volumetric injection rate, $Q_{T}$, is given, and the injection rates into each fracture, $Q_{i}$, are dynamically calculated by the model. The wellbore storage effect was ignored in the model. The sum of the injection rates of all the fractures is equal to the total injection rate,

$$
Q_{T}=\sum_{i=1}^{N} Q_{i}
$$

Kirchoff's second law described the continuousness of the pressure along the horizontal wellbore, considering the pressure drop of the wellbore friction and the perforation friction [21]. The sum of the pressure in the first element of a fracture branch, perforation friction pressure drop, and wellbore friction pressure drop together is equal to the pressure in the wellbore heel. The equation is given by:

$$
p_{o}=p_{p f, i}+p_{c f, i}+p_{w, i}
$$

where $p_{o}$ is the total pressure of the wellbore heel, $p_{w, i}$ is pressure of the first element of the fracture, $p_{p f, i}$ is the pressure loss of the perforation friction pressure loss, and $p_{c f, i}$ is the pressure loss of the horizontal wellbore. The identification number of the fracture branches is represented by ' $i$ '. The pressure drop of the perforation friction can be calculated by a function of the square of the flow rate and perforation friction. The lubrication theory was applied to describe the fluid flow in the fracture and the associated pressure drop. The model assumed that the fracture is a slot between parallel plates. Multiple fracture propagation has been simulated by the model and compared with a numerical model [22] to benchmark the accuracy of capturing the physical process of stress shadow effects.

\section{Case Study}

\subsection{Base Case}

In this section, we demonstrate the phenomenon of uneven fracture growth and how to facilitate a more uniform fracture propagation. The base case has three fractures propagating simultaneously in a single stage (Figure 1), which has a uniform cluster spacing of $23.3 \mathrm{~m}$. All parameters were selected from the Longmaxi formation of the Changning shale gas field in China and are listed in Table 1. We assume that one perforation cluster induces only one hydraulic fracture. Hence, the perforation-cluster spacing is the same as the initial-fracture spacing. The effects of the natural fractures and near-wellbore 
tortuosity are not taken into account. It is assumed that the reservoir is homogeneous in regard to slight differences of the in-situ stress state and rock mechanical properties. The final fracture geometry and flow volume distribution of the base case are shown in Figures 2 and 3, respectively. Because of the strong stress shadow effects, the middle fracture is much shorter, while the two exterior fractures are much longer. The average percentage of the flow rate into every cluster is $33 \%$. The middle fracture only received $19.6 \%$, which is much less than the intended percentage, while the exterior fractures received about $40.2 \%$ of the total fluid. The stress shadow effects and the friction pressure drop along the wellbore result in the curves of the interior and exterior fractures diverging. Based on the base case, we modified the values of the fracture spacing, perforating number, injection rate, fluid viscosity and number of fractures within the stage to analyze how these factors affect the effectiveness in promoting a uniform fracture growth. These parameters were changed one at a time from the base case.

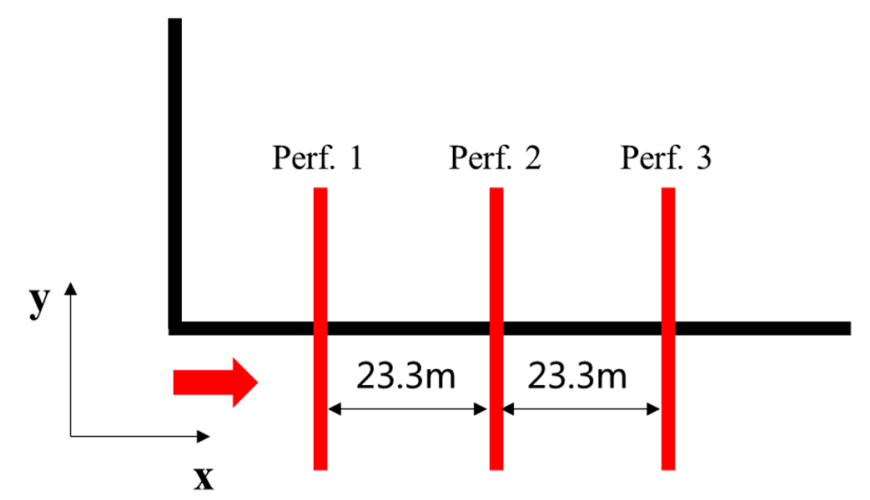

Figure 1. Three transverse fractures with a uniform spacing of $23.3 \mathrm{~m}$ in a single stage.

Table 1. Input parameters for simulation cases in this study.

\begin{tabular}{cccccc}
\hline Properties & Case 1 & Base Case & Case 2 & Case 3 & Unit \\
\hline Fracture spacing & 10 & 23.3 & 15 & 30 & $\mathrm{~m}$ \\
Perforation density/cluster & 12 & 16 & 20 & 24 & - \\
Injection rate & 10 & 12 & 14 & 16 & $\mathrm{~m}^{3} / \mathrm{min}$ \\
Fluid viscosity & 2.0 & 3.5 & 10 & 24 & $\mathrm{mPa} \cdot \mathrm{s}$ \\
Number of fractures within the stage & 2 & 3 & 4 & 5 & - \\
\hline
\end{tabular}

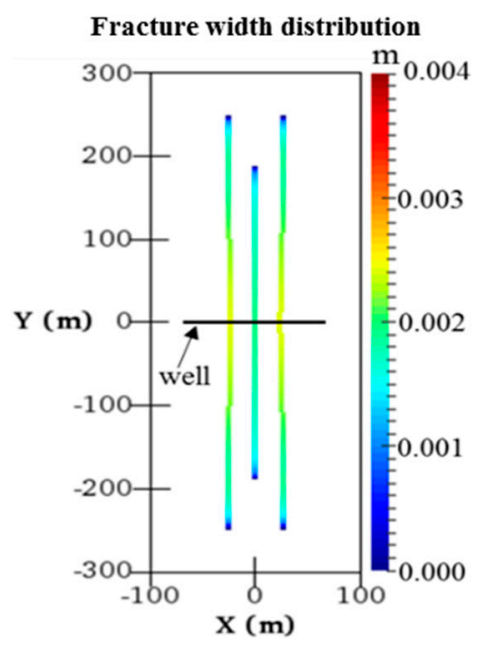

Figure 2. Three transverse fractures propagating simultaneously in a single stage. 


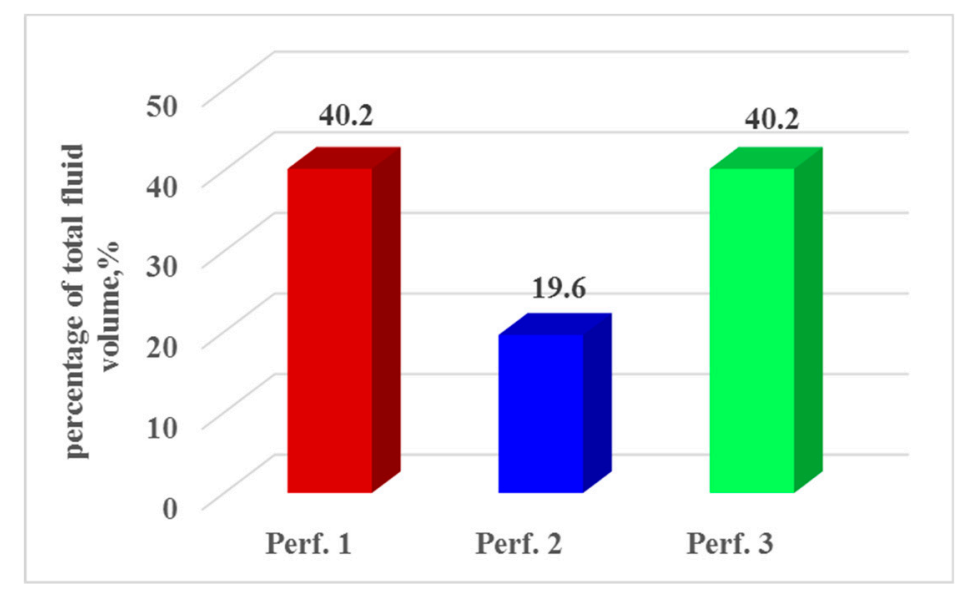

Figure 3. Percentage of total flow volume entering into each perforation cluster.

\subsection{Effect of Fracture Spacing}

With ultralow matrix permeability, one of the most effective ways to increase shale gas production is to optimize the number of fracture initiation points along the lateral. However, stress shadow effects can result from overly closely spaced fractures, resulting in an inefficient completion. Hence, we investigated three different fracture spacing effects on the fracture geometry and compared this with the base case. Each stage consists of three clusters, and the fracture spacings are $10 \mathrm{~m}, 15 \mathrm{~m}$, $23.3 \mathrm{~m}$, and $30 \mathrm{~m}$ (Figure 4), respectively. The simulation results show that the stress shadow effects increase with the decreasing fracture spacing, resulting in two longer outer fractures and a shorter middle fracture, as shown in Figure 5 and Table 2. The non-uniform fracture growth will significantly reduce the perforation efficiency. This is because larger stress shadow effects would increase the flow resistance of the middle fracture; less fluid enters into the middle fracture.

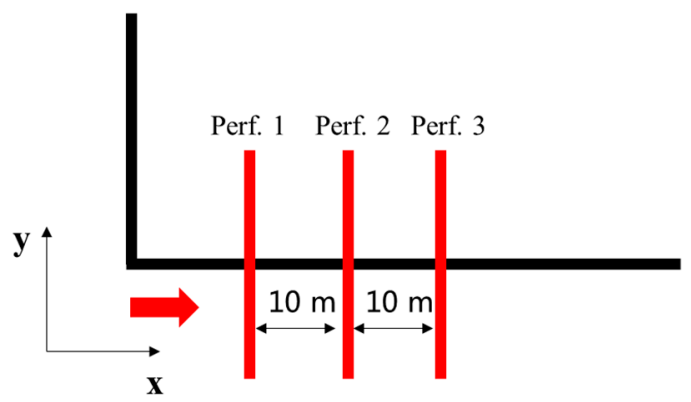

(a)

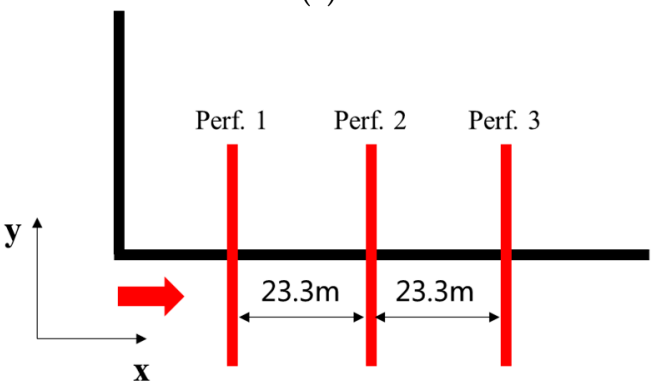

(c)

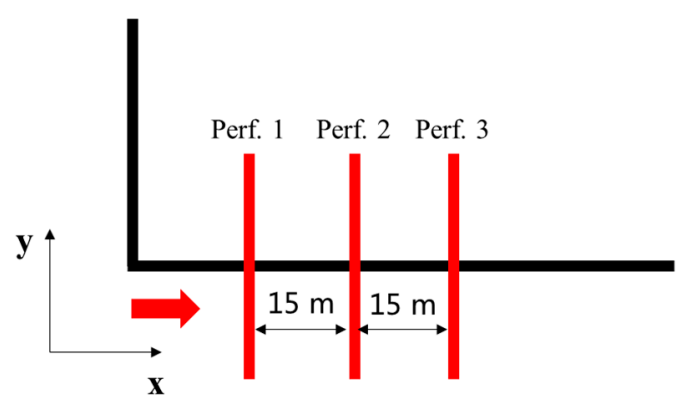

(b)

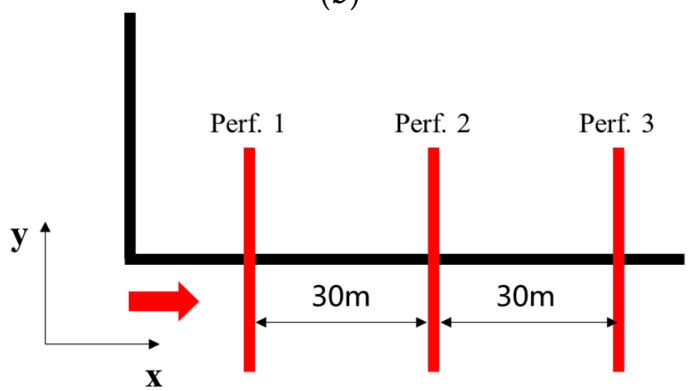

(d)

Figure 4. Different fracture spacings in a single stage: (a) $10 \mathrm{~m}$; (b) $15 \mathrm{~m}$; (c) $23.3 \mathrm{~m}$; and (d) $30 \mathrm{~m}$. 


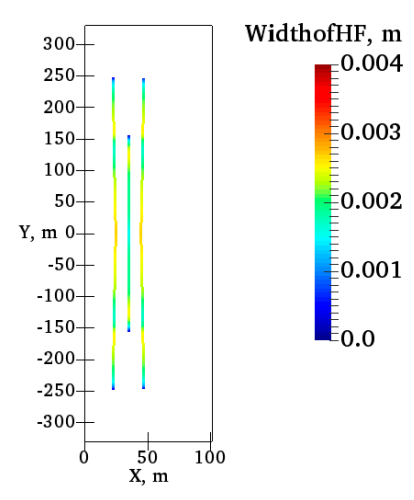

(a)

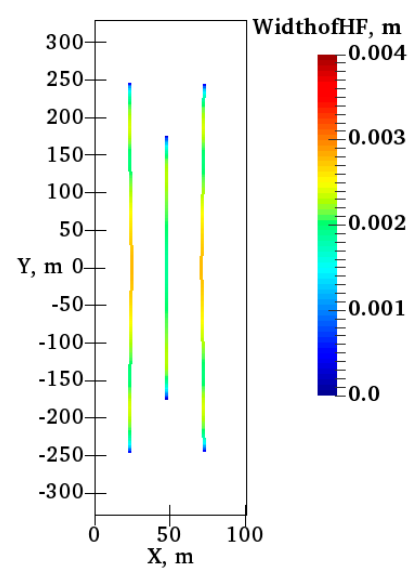

(c)

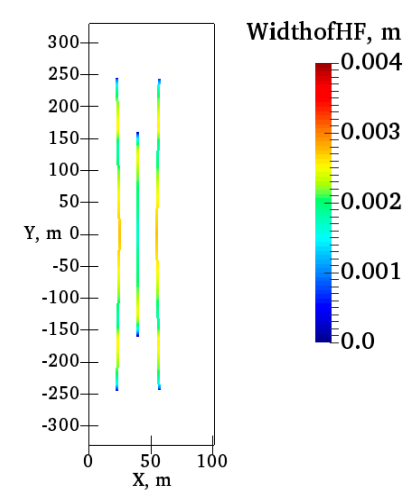

(b)

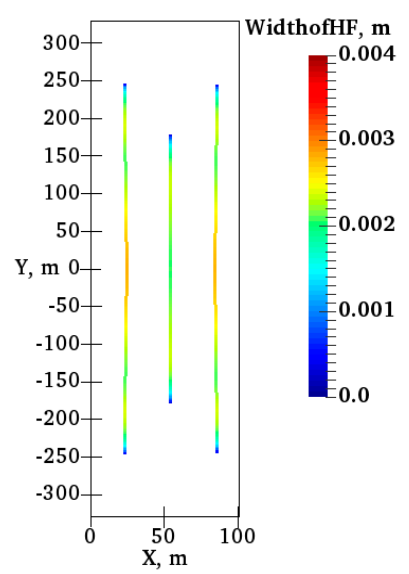

(d)

Figure 5. Effects of the different values of fracture spacing on the fracture geometry: (a) $10 \mathrm{~m}$; (b) $15 \mathrm{~m}$; (c) $23.3 \mathrm{~m}$; and (d) $30 \mathrm{~m}$.

Table 2. The results of fracture length affected by different cluster spacings.

\begin{tabular}{ccccc}
\hline Fracture Spacing, $\mathbf{~ m}$ & $\mathbf{1 5}$ & $\mathbf{2 3 . 3}$ & $\mathbf{1 0}$ & $\mathbf{3 0}$ \\
\hline The length of fracture 1, $\mathrm{m}$ & 490.1 & 492.6 & 495 & 492.6 \\
The length of fracture 2, $\mathrm{m}$ & 320.3 & 351.3 & 312.6 & 358.1 \\
The length of fracture 3, $\mathrm{m}$ & 488.3 & 489 & 494.1 & 487.3 \\
\hline
\end{tabular}

\subsection{Effect of Perforating Number}

Perforation friction is a function of perforation density. The base case has a uniform perforation design with 16 perforations for each cluster. In this subsection, three different cases were investigated: two of them increase to 20 and 24 perforations for each cluster respectively, and another case uses only 12 perforations for each cluster. Figure 6 and Table 3 illustrate that fractures grow more non-uniformly with the increasing perforation density for each cluster. The larger the perforation density, the shorter the middle fracture and the longer the two outer fractures. In addition, it can be found that 12 perforations per cluster for three clusters in one stage are the optimal design in the Changning shale gas field. While the perforation density for each cluster increases from 12 to 24 , the length of the middle fracture is reduced by $150 \%$ and the width is reduced by $25 \%$, which significantly decreases the cluster efficiency. 


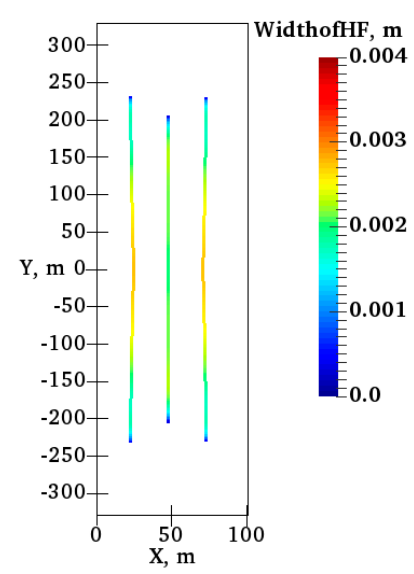

(a)

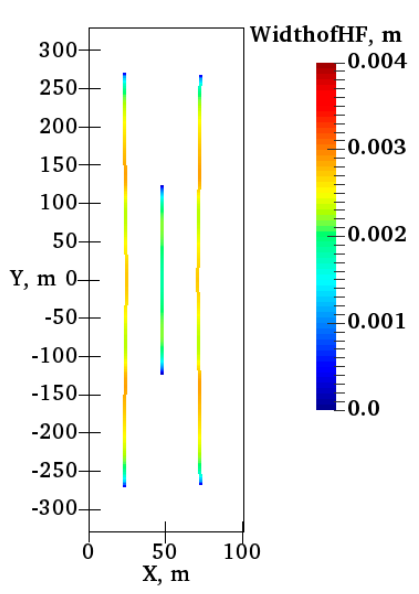

(c)

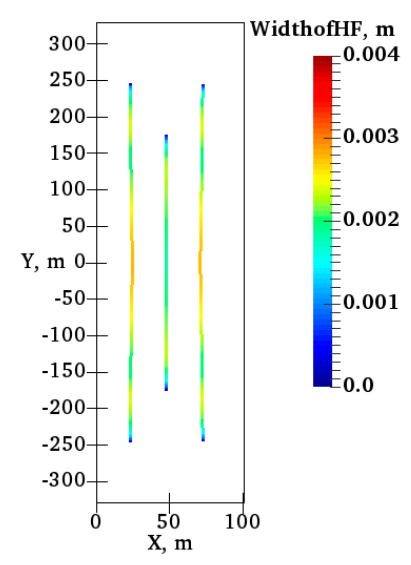

(b)

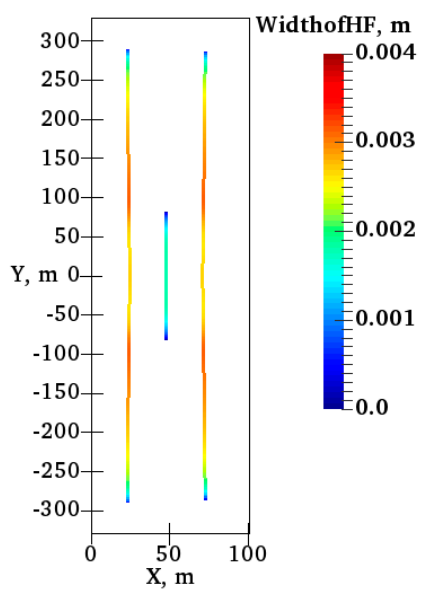

(d)

Figure 6. Effects of different perforations per cluster on the fracture geometry: (a) 12; (b) 16; (c) 20; and (d) 24 .

Table 3. The results of fracture length affected by different perforating numbers.

\begin{tabular}{ccccc}
\hline Perforating Number & $\mathbf{1 2}$ & $\mathbf{1 6}$ & $\mathbf{2 0}$ & $\mathbf{2 4}$ \\
\hline The length of fracture 1, $\mathrm{m}$ & 463.3 & 492.6 & 541.3 & 580.3 \\
The length of fracture 2, $\mathrm{m}$ & 410.1 & 351.3 & 246.5 & 163.1 \\
The length of fracture 3, $\mathrm{m}$ & 460.9 & 489 & 536.6 & 573.8 \\
\hline
\end{tabular}

\subsection{Effect of Injection Rate}

The injection rate is another important factor for affecting hydraulic fracturing treatments. Additionally, we kept other parameters the same as the base case and investigated the effects of different injection rates on the fracture geometry (Figure 7 and Table 4). Four injection rates were considered: $10 \mathrm{~m}^{3} / \mathrm{min}, 12 \mathrm{~m}^{3} / \mathrm{min}, 14 \mathrm{~m}^{3} / \mathrm{min}$ and $16 \mathrm{~m}^{3} / \mathrm{min}$. Since the injection time for all of the cases was the same, more fluid volume was injected for the larger injection rate. Figure 7 shows that a more uniform fracture geometry was achieved for the larger injection rate. The simulation results demonstrate that a higher injection rate is better for promoting a uniform fluid volume distribution and an even growth for each cluster in the Changning shale gas field. This is because that larger injection rate can mitigate stress shadow effects and generate a higher perforation friction pressure 
drop. Consequently, the injection rate of the Changning shale gas field should be increased to improve the cluster efficiency.

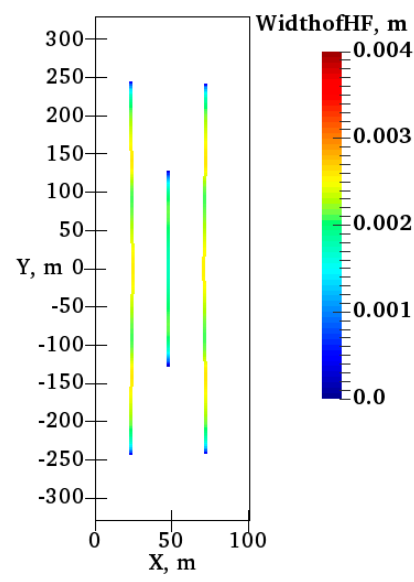

(a)

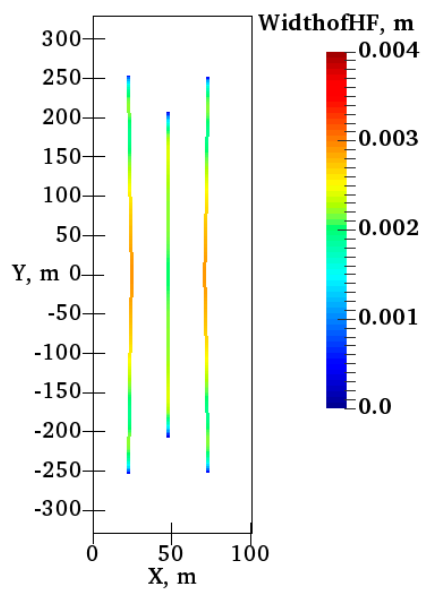

(c)

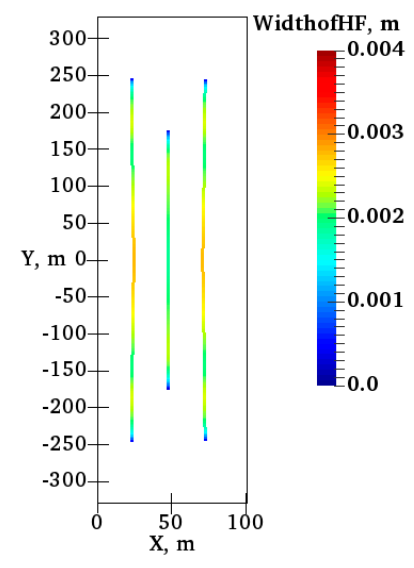

(b)

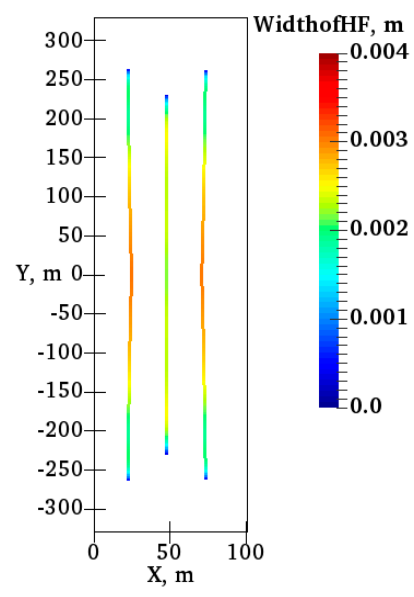

(d)

Figure 7. Effects of different injection rates on the fracture geometry: (a) $10 \mathrm{~m}^{3} / \mathrm{min}$; (b) $12 \mathrm{~m}^{3} / \mathrm{min}$; (c) $14 \mathrm{~m}^{3} / \mathrm{min}$; and (d) $16 \mathrm{~m}^{3} / \mathrm{min}$.

Table 4 . The results of fracture length affected by different injection rates.

\begin{tabular}{ccccc}
\hline Injection Rate, $\mathbf{~ m}^{\mathbf{3}} / \mathbf{m i n}$ & $\mathbf{1 0}$ & $\mathbf{1 2}$ & $\mathbf{1 4}$ & $\mathbf{1 6}$ \\
\hline The length of fracture 1, $\mathrm{m}$ & 487.7 & 492.6 & 507.2 & 526.7 \\
The length of fracture 2, $\mathrm{m}$ & 255.1 & 351.3 & 413.8 & 460.4 \\
The length of fracture 3, $\mathrm{m}$ & 484 & 489 & 503.6 & 523.3 \\
\hline
\end{tabular}

\subsection{Effect of Fluid Viscosity}

We studied the effects of different fluid viscosities on the fracture geometry, and the simulation results are shown in Figure 8. The other parameters are the same as those of the base case. The three different viscosities of the injection fluid are, respectively, $2.0 \mathrm{mPa} \cdot \mathrm{s}, 10 \mathrm{mPa} \cdot \mathrm{s}$ and $24 \mathrm{mPa} \cdot \mathrm{s}$. An injection fluid with a larger viscosity created a higher fluid pressure within the fracture and a wider fracture width (Figure 8 and Table 5). A higher fluid pressure generated stronger stress shadow effects, resulting in a larger variation of fluid distribution between perforation clusters. Figure 8 illustrates that the length of the middle fracture is reduced by $40.6 \%$, and the width increases by $76 \%$, when the 
fluid viscosity increases from $2.0 \mathrm{mPa} \cdot \mathrm{s}$ to $24 \mathrm{mPa} \cdot \mathrm{s}$. For that reason, the viscosity of the injection fluid should be decreased to $2.0 \mathrm{mPa} \cdot \mathrm{s}$ in the Changning shale gas field.

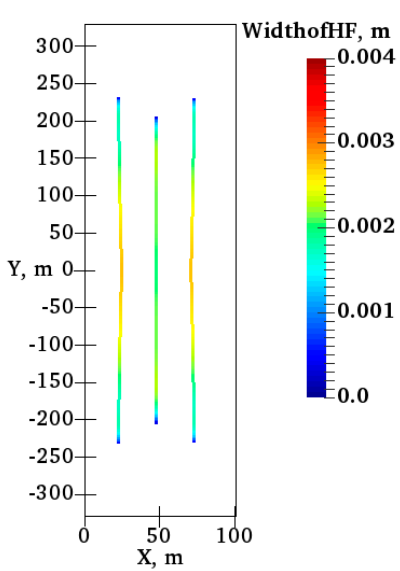

$(\mathbf{a})$

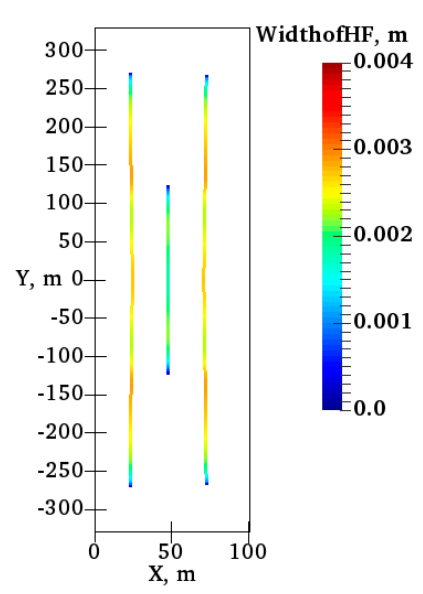

(c)

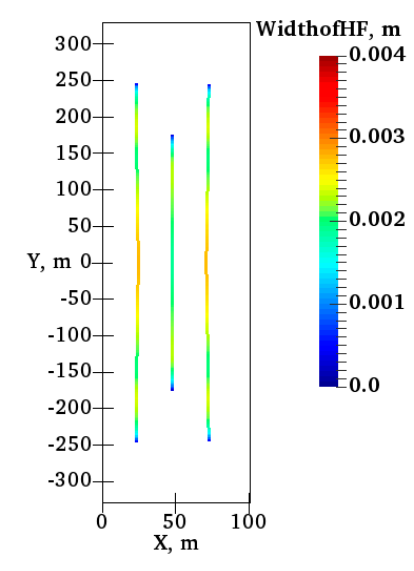

(b)

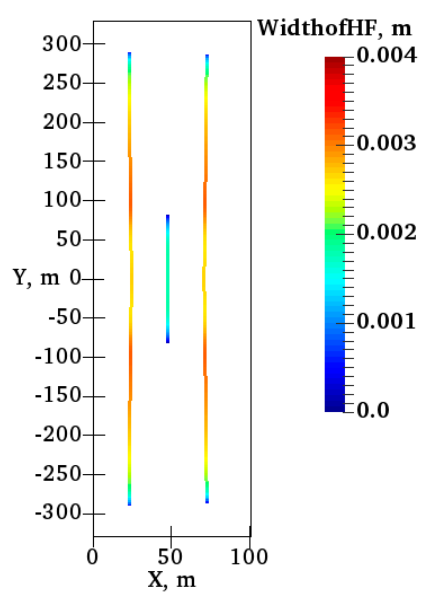

(d)

Figure 8. Effect of fluid viscosity on the fracture geometry: (a) $2 \mathrm{mPa} \cdot \mathrm{s}$; (b) $3.5 \mathrm{mPa} \cdot \mathrm{s}$; (c) $10 \mathrm{mPa} \cdot \mathrm{s}$; and (d) $24 \mathrm{mPa} \cdot \mathrm{s}$.

Table 5. The results of fracture length affected by different fluid viscosities.

\begin{tabular}{ccccc}
\hline Fluid Viscosity, $\mathbf{m P a} \cdot \mathbf{s}$ & $\mathbf{2 . 0}$ & $\mathbf{3 . 5}$ & $\mathbf{1 0}$ & $\mathbf{2 4}$ \\
\hline The length of fracture 1, $\mathrm{m}$ & 487.7 & 492.6 & 512.1 & 531.6 \\
The length of fracture 2, $\mathrm{m}$ & 377.4 & 351.3 & 288.5 & 224.3 \\
The length of fracture 3, $\mathrm{m}$ & 485.5 & 489 & 503.0 & 511.7 \\
\hline
\end{tabular}

\subsection{Effect of Number of Fractures Within the Stage}

The number of fractures within the stage is an important factor of hydraulic fracturing treatments, which is the most effective way to increase production in the Haynesville [14]. Therefore, we studied the impacts of different cluster numbers on the fracture geometry in a single stage. Under the condition of the fixed stage length of $70 \mathrm{~m}$, the cluster number of four cases is, respectively, 2, 3, 4 and 5, while the other parameters are the same as the base case. The simulation results are shown in Figure 9 and Table 6. They illustrate that as the cluster number within the stage increases, the cluster spacing decreases, and the stress shadow effects increase, leading to a longer total fracture length and shorter 
average fracture width. The optimal number of clusters in a single stage needs to be determined in combination with the production simulation and economic evaluation. However, according to the simulation results, if more than 4 clusters within the stage are used, one needs to utilize the intrastage diversion techniques $[23,24]$ to enhance cluster efficiency in the Changning shale gas field.

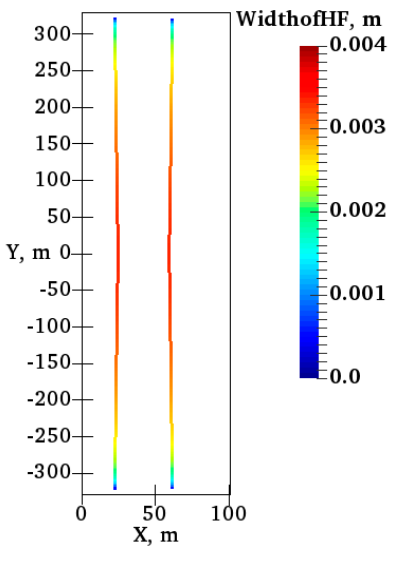

(a)

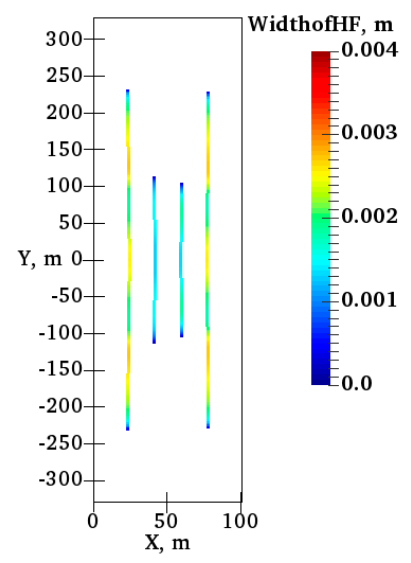

(c)

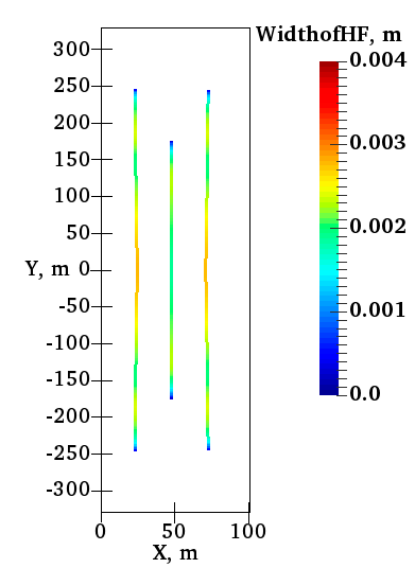

(b)

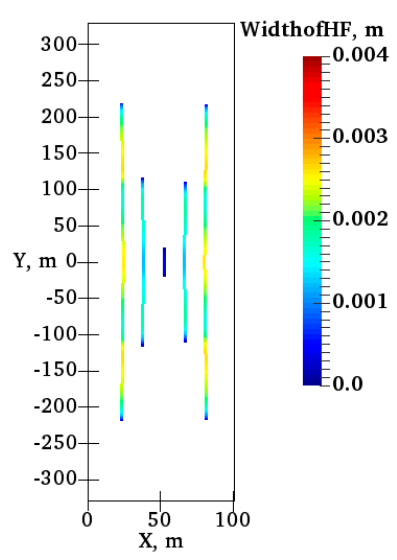

(d)

Figure 9. Effects of different numbers of fracture within the stage on the fracture geometry: (a) 2; (b) 3; (c) 4 ; and (d) 5 .

Table 6. The results of fracture length affected by different number of fractures within the stage.

\begin{tabular}{ccccc}
\hline Number of Fractures within the Stage & $\mathbf{2}$ & $\mathbf{3}$ & $\mathbf{4}$ & $\mathbf{5}$ \\
\hline The length of fracture 1, m & 643.7 & 492.6 & 463.3 & 438.5 \\
The length of fracture 2, m & 641.7 & 351.3 & 226.5 & 232.7 \\
The length of fracture 3, m & & 489 & 210.9 & 39.4 \\
The length of fracture 4, m & & & 457.6 & 220.9 \\
The length of fracture 5, m & & & & 434.3 \\
\hline
\end{tabular}

\section{Discussions}

In order to evaluate the effects of the fracture spacing, perforating number, injection rate, fluid viscosity, and number of fractures within the stage on the fracture geometry in the Changning shale gas field, we defined a deviation of the normalized fracture length [25]. This sequence can indicate the main controlling factors for the effectiveness of fracture treatments. First, according to the basic input parameters, the average fracture length in the example is calculated. Then, we calculated 
the deviation of the three fractures. In the same way, we calculated the maximum and minimum deviation corresponding to the maximum and minimum values of each uncertain parameter. Finally, we sorted each uncertain parameter according to the maximum and minimum deviation values. Based on the sorting result and the deviation of the normalized fracture length, the Tornado plot (Figure 10) was obtained. The $x$-axis is the calculated deviation of the normalized fracture length and represents the effects of uncertain parameters on the uniformity of the fracture growth. The order of uncertain parameters in the $y$-axis was determined by the absolute difference between the maximum and minimum deviation of the normalized fracture length. The green bar represented a positive effect and the black bar represented a negative effect. The middle mark represented the deviation of the normalized fracture length of the base case. The Tornado plot shows that the number of fractures within the stage is the most important parameter for affecting the fracture geometry in the Changning shale gas field. A larger variation of fracture geometry will be created with either the increasing number of fractures, the decreasing flow rate, the increasing perforating number or the increasing fluid viscosity. The fracture spacing has a relatively smaller impact on the fracture geometry. It should be mentioned that the spatial variations of the stress state, natural fractures and near wellbore tortuosity are not considered in this study, but will be examined in our future work. Therefore, we should improve the number of fractures in the stage with the intrastage diversion techniques. In addition, 16 $\mathrm{m}^{3} / \mathrm{min}$ of flow rate, 12 perforations for each cluster and an injection fluid with $2.0 \mathrm{mPa} \cdot \mathrm{s}$ are better for improving the effectiveness of the stimulation treatments in the Changning shale gas field.

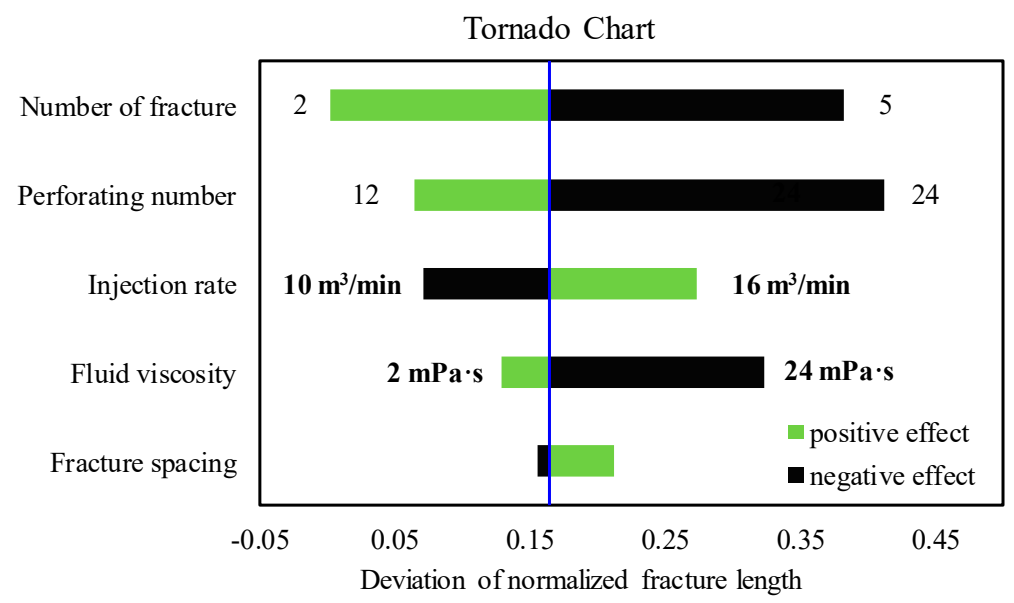

Figure 10. Rank of five uncertain parameters on the deviation of the normalized fracture length.

\section{Conclusions}

We applied a complex fracture propagation model to simulate multiple fracture propagation in the Changning shale gas field. The effects of the fracture spacing, perforating number, injection rate, fluid viscosity, and number of fractures within the stage on the fracture geometry were investigated based on field data from the Longmaxi shale formation in the Changning shale gas reservoir. The following conclusions can be drawn from this study:

(1) The main factors for controlling the cluster efficiency in the Changning shale gas field are the cluster numbers, the perforation density, the injection rate, and the liquid viscosity.

(2) Hydraulic fracture treatments with more than four clusters per stage, a lower injection rate, larger perforating number, larger viscosity fluid, and closer fracture spacing can result in an increasing gap between the inner fracture and outer fractures, and they will likely exhibit a bad production performance.

(3) This study provides a better understanding of the way to appropriately optimize a hydraulic fracturing treatment design which can increase the effective fracture number and promote the shale gas well performance in Changning. 
Author Contributions: Conceptualization, J.X. and H.H.; methodology and investigation W.Y. and K.W.; writing-original draft preparation, H.H.; writing—review and editing, Y.S. and Y.F.; project administration, J.C.; funding acquisition, Y.S. and Y.F.

Funding: This research was funded by "National Science and Technology Major Project of China, grant number 2016ZX05023-005-00" and "The Chinese Academy of Engineering Key Consulting Research Project, grant number 2018-XZ-20" and "Major Science and Technology Special Project of CNPC, grant number 2016E-0612".

Conflicts of Interest: The authors declare no conflict of interest.

\section{References}

1. Xie, J. Rapid shale gas development accelerated by the progress in key technologies: A case study of the Changning-Weiyuan national shale gas demonstration zone. J. Nat. Gas Ind. 2018, 5, 283-292. [CrossRef]

2. Cadotte, R.J.; Whitsett, A.; Sorrell, M.; Hunter, B. Modern Completion Optimization in the Haynesville Shale. In Proceedings of the SPE Annual Technical Conference and Exhibition, San Antonio, TX, USA, 9-11 October 2017; Society of Petroleum Engineers: Richardson, TX, USA, 2017.

3. Engelder, T.; Lash, G.G.; Uzcategui, R.S. Joint sets that enhance production from Middle and Upper Devonian gas shales of the Appalachian Basin. AAPG Bull. 2009, 93, 857-889. [CrossRef]

4. Yu, W.; Wu, K.; Liu, M.; Sepehrnoori, K.; Miao, J. Production forecasting for shale gas reservoirs with nanopores and complex fracture geometries using an innovative non-intrusive EDFM method. In Proceedings of the SPE Annual Technical Conference and Exhibition, Dallas, TX, USA, 24-26 September 2018.

5. Shou, K.J. A High Order Three-Dimensional Displacement Discontinuity Method with Application to Bonded Half-Space Problems. Ph.D. Dissertation, University of Minnesota, Minneapolis, MN, USA, 1993.

6. Siriwardane, H.J.; Layne, A.W. Improved Model for Predicting Multiple Hydraulic Fracture Propagation from a Horizontal Well. Presented at the SPE Eastern Regional Meeting, Lexington, KY, USA, 22-25 October 1991. [CrossRef]

7. Weng, X. Modeling of Complex Hydraulic Fractures in Naturally Fractured Formation. J. Unconv. Oil Gas Resour. 2015, 9, 114-135. [CrossRef]

8. Yan, C.; Deng, J.; Hu, L.; Chen, Z.; Yan, X.; Lin, H.; Tan, Q.; Yu, B. Brittle failure of shale under uniaxial compression. Arab. J. Geosci. 2015, 8, 2467-2475.

9. Dong, Z.; Holditch, S.A.; Mcvay, D.A. Resource evaluation for shale gas reservoirs. In Proceedings of the SPE Hydraulic Fracturing Technology Conference, The Woodlands, TX, USA, 6-8 February 2012.

10. Thompson, J.; Fan, L.; Grant, D.; Martin, R.B.; Kanneganti, K.T.; Lindsay, G.J. An overview of horizontal-well completions in the Haynesville Shale. J. Can. Pet. Technol. 2011, 50, 22-35. [CrossRef]

11. Warpinski, N.R.; Mayerhofer, M.J.; Davis, E.J.; Holley, E.H. Integrating fracturing diagnostics for improved microseismic interpretation and stimulation modeling. In Proceedings of the URTeC 1917906, the Unconventional Resources Technology Conference, Denver, CO, USA, 25-27 August 2014.

12. Olson, J.E.; Wu, K. Sequential versus Simultaneous simultaneous Multimulti-zone Fracturing fracturing in Horizontal horizontal Wellswells: Insights insights from a Nonnon-planar, Multimulti-frac Numerical numerical Modelmodel. Presented at the SPE Hydraulic Fracturing Technology Conference, The Woodlands, TX, USA, 6-8 February 2012.

13. Kan, W.; Anusarn, S.; Tang, J. Numerical study of flow rate distribution for simultaneous multiple fracture propagation in horizontal wells. In Proceedings of the 50th US Rock Mechanics/Geomechanics Symposium, Houston, TX, USA, 26-29 June 2016; American Rock Mechanics Association: Alexandria, VA, USA, 2016.

14. Sani, A.M.; Podhoretz, S.B.; Chambers, B.D. The Use of Completion Diagnostics in Haynesville Shale Horizontal Wells to Monitor Fracture Propagation, Well Communication, and Production Impact. In Proceedings of the SPE/CSUR Unconventional Resources Conference, Calgary, AB, Canada, 20-22 October 2015; Society of Petroleum Engineers: Richardson, TX, USA, 2015.

15. Ugueto, C.; Gustavo, A.; Huckabee, P.T.; Molenaar, M.M.; Wyker, B.; Somanchi, K. Perforation cluster efficiency of cemented plug and perf limited entry completions; Insights from fiber optics diagnostics. In Proceedings of the SPE Hydraulic Fracturing Technology Conference, The Woodlands, TX, USA, 9-11 February 2016; Society of Petroleum Engineers: Richardson, TX, USA, 2016. 
16. Guo, X.; Wu, K.; Killough, J.; Tang, J. Understanding the mechanism of interwell fracturing interference based on reservoir-geomechanics-fracturing modeling in Eagle Ford Shale. In Proceedings of the Unconventional Resources Technology Conference, Houston, TX, USA, 23-25 July 2018; Society of Exploration Geophysicists, American Association of Petroleum Geologists, Society of Petroleum Engineers: Richardson, TX, USA, 2018; pp. 4097-4117.

17. Li, J.; Yu, W.; Wu, K. Analyzing the impact of fracture complexity on well performance and wettability alteration in Eagle Ford shale. In Proceedings of the Unconventional Resources Technology Conference, Houston, TX, USA, 23-25 July 2018; Society of Exploration Geophysicists, American Association of Petroleum Geologists, Society of Petroleum Engineers: Richardson, TX, USA, 2018; pp. 2072-2086.

18. Patterson, R.; Yu, W.; Wu, K. Integration of microseismic data, completion data, and production data to characterize fracture geometry in the Permian Basin. J. Nat. Gas Sci. Eng. 2018, 56, 62-71. [CrossRef]

19. Wu, K. Numerical Modeling of Complex Hydraulic Fracture Development in Unconventional Reservoirs. Ph.D. Dissertation, The University of Texas, Austin, TX, USA, 2014.

20. Wu, K.; Olson, J.E. Simultaneous Multi-Frac Treatments: Fully Coupled Fluid Flow and Fracture Mechanics for Horizontal Wells. SPE J. 2015, 20, 337-346. [CrossRef]

21. Elbel, J.L.; Piggott, A.R.; Mack, M.G. Numerical modeling of multilayer fracture treatments. In Proceedings of the SPE Permian Basin Oil and Gas Recovery Conference, Midland, TX, USA, 18-20 March 1992.

22. Wu, R.; Kresse, O.; Weng, X.; Cohen, C.; Gu, H. Modeling of interaction of hydraulic fractures in complex fracture networks. In Proceedings of the SPE Hydraulic Fracture Technology Conference, The Woodlands, TX, USA, 6-8 February 2012.

23. Xiong, H.; Wu, W.; Gao, S. Optimizing Well Completion Design and Well Spacing with Integration of Advanced Multi-Stage Fracture Modeling \& Reservoir Simulation-A Permian Basin Case Study. In Proceedings of the SPE Hydraulic Fracturing Technology Conference and Exhibition, Woodlands, TX, USA, 23-25 January 2018.

24. Huang, J.; Datta-Gupta, A.; Augustine, J.R. Optimization of hydraulic fracture development and well performance using limited entry perforations. In Proceedings of the SPE Oklahoma City Oil and Gas Symposium, Oklahoma City, OK, USA, 27-31 March 2017; Society of Petroleum Engineers: Richardson, TX, USA, 2017.

25. $\mathrm{Wu}, \mathrm{K}$; Olson, J.E. Numerical Investigation of complex fracture networks in naturally fractured reservoirs. SPE Prod. Oper. 2016, 31, 300-309. 